\title{
EFFECT OF DEFAULTS AND CREDIT DETERIORATION ON YIELDS OF CORPORATE BONDS
}

\author{
Harold G. Fraine and Robert H. Mills \\ University of Wisconsin and University of Michigan
}

THE AUTHORS WERE faced with the problem of estimating the size of reserve which would have been necessary for absorbing losses on medium- and high-grade corporate bonds during the first half of this century. Upon searching the literature to see what help could be gained from past authorities, we found that there is a gap between the doctrines by theorists as to the kind of experience expectable and the best published statistics of realized yields and loss rates. ${ }^{1}$ We are passing along the results of a small effort to plug this gap in the hope that it will help others who are similarly faced with the necessity of using the record of the past performance of corporate bonds in connection with problems of evaluation of probable future performance.

Theorists in the field of investments seem generally to offer support for the idea that some reserve is desirable. This is found in such doctrines that, in contrast with common stocks, where either gain or loss may be expected, the nature of the contract in unconvertible corporate bonds severely limits the possibilities of gain but leaves quite open the possibilities of loss up to 100 per cent. Again, there is the doctrine that bond investment is a "negative art," requiring principally the gauging of the chances for loss and the estimating of what premium in yield is appropriate for acceptance of those chances. Many writers have regarded the difference between the prospective yield from market price on a bond and the yield prevailing at the same time on riskless securities of similar term as consisting mainly

1. The best published statistics on the realized yields and loss rates on corporate bonds are in W. Braddock Hickman, Corporate Bond Quality and Investor Experience and Statistical Measures of Corporate Bond Financing (Princeton: Princeton University Press, 1959 and 1960, respectively). Inasmuch as our purpose is to supplement and build upon the material already published by Mr. Hickman, our debt to him is obvious. We are also deeply indebted to the National Bureau of Economic Research for tabulating individual yields from their punched cards in such a manner as to permit the derivation of our "modified" realized yields and loss rates-particularly to Dr. Geoffrey Moore for his stimulating ideas and to Miss Elizabeth T. Simpson, whose grasp of our problem and knowledge of the basic records were extremely helpful. Grateful acknowledgment is made to Robert Morrison, William Dawn, and Gary L. Swenson, graduate students at the University of Wisconsin, for statistical assistance. 
of premium offered the investor for assuming risk of later loss. This sort of theory reached perhaps its most extreme form in the writings of Kirshman, who implied that, within a diversified portfolio of bonds, sufficiently large for averages to work out, greater losses would later be incurred among the bonds of higher-risk premiums which would reduce their average realized yield below the prospective, probably down to the level of the prospective yields prevailing on only the riskless ones. ${ }^{2}$ Thus there is the implication that the interest receipts in excess of those on the safest bonds should not be regarded as income but as an offset to losses expected to be experienced on the portfolio of such bonds later when defaults occur and that, for the institutional investor capable of reserving income, such risk premiums presumably indicate the proper rates of reservation for later losses.

Turning now to the literature on statistics of yields of corporate bonds, most of the published statistics have been, as in the case of Macaulay $^{3}$ and Durand, ${ }^{4}$ in terms of the prospective yields-looking forward from market prices in anticipation of performance according to the contract. Such yields might also be characterized as "ex ante," "expected," "anticipatory," or "market" yields. There has been a growing literature reflecting attempts to contrast such anticipatory yields with yields which measure the departures of actual from anticipated performance. ${ }^{5}$ This latter type of yield is variously characterized as "actual," "realized," "ex post," or "lifespan" yields. And the deficiencies of the ex post from the ex ante yields-of the realized from the prospective yields-have been characterized as "loss rates"-measuring the rates of annual reservations from interest receipts which would have been necessary in order to offset subsequent losses. Such realized yields and loss rates have been computed not only for various categories of corporate bonds but also for varying length and calendar terminal points of

2. J. E. Kirshman, Principles of Investment (New York: McGraw-Hill Book Co, Inc., 1933), pp. 95, 109-10.

3. Frederick A. Macaulay, Interest Rates, Bond Yields, and Stock Prices (New York: National Bureau of Economic Research, 1938).

4. David Durand, "Basic Yields of Corporate Bonds, 1900-1942" (Technical Paper No. 3 [New York: National Bureau of Economic Research, 1942]).

5. For some "pre-Hickman" studies involving "realized" yields, see A. S. Dewing, The Financial Policy of Corporations (New York: Ronald Press, 1926), pp. 1194-95; H. G. Fraine, "Superiority of High-Yield Bonds Not Substantiated by 1927-1936 Performance," Annalist (New York Times Publishing Co.), October 1, 1937; Leo Spurrier, "Common Stocks and Bonds as Long-Term Investments," Journal of Business (January, 1941), XIV, 9. 
assumed periods of holding. They have been computed on the basis of holding from issue to extinguishment of the contract, as well as on the basis of purchase on certain dates and sale at other dates. For the purpose of measuring default risk, the measures covering holdings during the years of the depression of the 1930's are most useful because during that period bonds suffered as much from default and value depreciation as seems likely ever to be experienced in the future. The period of the thirties is thus regarded as furnishing a sort of acid test.

All the various realized yields for which statistics have been published have one characteristic in common. They reflect the effects on realized yields of money-market changes just as readily as they do effects of credit impairment or default. The realized yields are increased above the prospective yields by reason of calls for redemption at prices higher than the maturity value, as well as lowered below the prospective yield as the result of impairments in the payment of interest or principal. For bonds outstanding on a date of assumed market liquidation, as at the end of a period of study, the realized yields are pushed above the prospective yields if the market rate of interest at such a time is below the market level at the time of assumed purchase, as well as pushed below the prospective yields by declines in market values by reason of impairment of the credit standing of the debtor. The published realized-yield statistics which average these diverse effects are found to be very reassuring by some institutional investors, who cite them as evidence that the history of this period of admittedly acid test indicates that no reserve is necessary.

Those taking this position are fond of citing that the most comprehensive and useful publication of such yields shows that the average realized yield on a representative portfolio of corporate bonds of the four highest agency rating grades during the span of years from early 1900 to early 1944 was actually in excess of, instead of deficient from, the prospective yield, in spite of the facts that in each of those years actual interest payments were less than contracted for ${ }^{6}$ and that the proportion of all outstanding straight corporate bonds in default reached as high as about 15 per cent in 1936 and $1940 .{ }^{7} \mathrm{Had}$ the large issues of the top four rating grades run to

6. See W. Braddock Hickman, The Volume of Corporate Bond Financing since 1900 (Princeton: Princeton University Press, 1953), Table A-25, p. 380.

7. Calculated from Tables A-2 and A-17 of Hickman, ibid., pp. 257 and 340. 
maturity with interest and principal payments unimpaired, they would have given the investor a yield of 4.8 per cent. ${ }^{8}$ In spite of some bonds defaulting and many others declining in liquidating value because of impairment of credit condition, the average ${ }^{9}$ realized yield for the entire group was 5.2 per cent. ${ }^{8}$ Some investors are unduly impressed by the fact that, instead of an expected loss rate, there was an average rate of gain of the realized over the prospective yield of 0.4 per cent per annum $(5.2-4.8)$. Such a result is at least superficially contrary to the theoretical doctrines and came about, of course, because the gains in redemption values and final market values of many bonds, due mainly to changes in moneymarket conditions, more than offset the defection of the realized from the prospective yields of other bonds within the portfolio caused by defaults in interest and principal payments and by depreciation in final liquidation value due to deterioration in credit prospects. Hickman says:

Thus, if all of the bond issues in this study are conceived of as pooled into a single portfolio held from offering to extinguishment or 1944, the portfolio would have suffered no loss in current dollars. This is a truly remarkable finding in view of the fact that the record spans a period of forty-four years that includes a great war and a great depression. ${ }^{10}$

For the purpose of estimating the reserve needs of large-scale continuing investors, it was desired to supplement the already published realized yields and loss rates with "modified" realized yields and loss rates which reduce, though do not completely remove, the effect of money-market influences on final liquidation values. To continuing investors the retirement of an issue before maturity at a premium over the maturity payment is usually a disadvantage rather than an advantage, because retirements by call are usually at the option of the issuer rather than the investor and are usually under conditions which are advantageous to the issuer and disadvantageous to the investor-namely, when the market rate of interest for refunding and therefore for reinvestment in the same degree of risk is lower than the contract rate in the security already outstanding. Under such circumstances reinvestment at the same degree of risk usually involves a loss on the reinvestment much

8. Hickman, Statistical Measures, p. 394.

9. Mean of individual percentage annual yields of individual bonds weighted by dollar volume at issuance. For detailed background on the computation and averaging of bond yields, see Hickman, Bond Quality, pp. 54-66.

10. Ibid., p. 73. 
greater than the gain on liquidation of the issue which is terminated. ${ }^{11}$ For the continuing investor, the call premium is, in effect, inadequate "liquidated damages" for loss to be suffered on reinvestment.

That there was a drastic decline in rates earned on invested funds by life insurance companies during the period of abnormally high calls and refundings of the 1930's and 1940's can be noted from Table 1. The realized yields now available in the literature are affected not only by calls but also by the market prices assumed for purchase or liquidation of bonds outstanding at terminal dates of the study rec-

TABLE 1

Net Rates EARNED on INVESTED LIFE INSURANCE Company Funds (Per Cent)*

\begin{tabular}{|c|c|c|c|c|c|}
\hline Year & Rate & Year & Rate & Year & Rate \\
\hline 1920. & 4.83 & 1930 & 5.05 & 1940. & 3.45 \\
\hline 1921. & 5.02 & 1931 & 4.93 & 1941. & \\
\hline 1922. & 5.12 & 1932 & 4.65 & 1942 . & \\
\hline 1923. & 5.18 & 1933 & 4.25 & 1943. & 3.2 \\
\hline 1924. & 5.17 & 1934 & 3.92 & 1944. & 3.19 \\
\hline 1925. & 5.11 & 1935 & 3.70 & 1945. & 3.07 \\
\hline 1926. & 5.09 & 1936 & 3.71 & 1946 & 2.92 \\
\hline 1927. & 5.05 & 1937 & 3.69 & 1947. & \\
\hline 1928. & 5.05 & 1938 & 3.59 & 1948 & 2.9 \\
\hline 1929. & 5.05 & 1939 & 3.54 & 1949. & 3.04 \\
\hline
\end{tabular}

* From Life Insurance Fact Book, 1952 (New York: Institute of Life Insurance, 1953), p. 49.

ord. Hickman was obviously concerned with the possible distortion of yields caused by unprecedentedly low interest rates, hence by unprecedentedly high bond prices on the date of assumed liquidation in the market of the population of bonds still outstanding at the end of the study period. He dealt with the difficulty by breaking up or refining his population in different ways, but without modifying the realized yields. He shows, for example, that when the issues outstanding at the termini of the study are excluded and the popu-

11. The following hypothetical illustration uses interest-rate changes that are within the record of recent experience: Assume an investor purchases at par $\$ 1,000,000$ of $4 \frac{1}{2}$ per cent bonds due in thirty years at par but callable in ten years at 105. The prospective yield would be 4.5 per cent. Assume that, ten years later, interest rates for that degree of risk decline to 3 per cent and that the bonds are called by the issuer. The investor would then receive $\$ 1,050,000$. This would appear to represent a capital gain of $\$ 50,000$. The reinvestment of the $\$ 1,050,000$ would have to be at the lower interest rates prevailing, namely, 3 per cent for comparable quality securities. Upon reinvestment, there would be a decline in annual interest receipts from $\$ 45,000$ to $\$ 31,500$ (3 per cent $\times \$ 1,050,000$ ), or an income loss of $\$ 13,500$ annually. The $\$ 270,000$ loss $(20 \times \$ 13,500)$ in income over the twenty years foregone of the old contract is substantially greater than the $\$ 50,000$ premium received on the call of the old bonds. And the new bond, because of its lower coupon rate, would have less chance of eventual liquidation above maturity value. 
lation confined to issues which were both issued and extinguished within the span of years of the study,

... the loss rate rises from -0.1 per cent (inferring capital gains) to 0.1 per cent (inferring capital losses). The implication would seem to be that investors who are unable to take advantage of market appreciation on outstanding issues (but are required by statute to write securities down to market under certain circumstances) would require somewhat higher loss reserves than those needed by investors generally. So far as can be judged from the record before us, a reserve accumulated at the rate of 0.1 per cent on book value would have been adequate to take care of default losses on large issues offered and extinguished within the period studied. ${ }^{12}$

This refinement is at the cost of omitting, from averaging, the yields of the great population of bonds outstanding at the end of the record, some of which were still suffering from credit impairment and from failure to complete reorganization following default. Also, it still leaves in the record the abnormally high gains from calls, which also resulted from the drop in interest rates. Most of the bonds extinguished during this period were extinguished by call. The calls at premiums were allowed to push the realized yields above the prospective yields. Inasmuch as most of such retirements were toward the end of the period, reinvestment would have been made in bonds which were issued at such low interest rates as not so likely in turn to be redeemed at premiums. The abnormality of the volume of redemption at premiums is indicated by the fact that the average proportion of redemptions by call during the latter half of the period studied was about ten times that of the earlier half. ${ }^{13}$ The problem is to retain the successful along with the unsuccessful bonds without retaining the gains in realized yields caused by the change in level of interest rates.

In order to retain as much as possible of the effects of defaults and impairment of credit prospects and eliminate as much as possible of the effects of purely money-market influences, the authors have derived "modified" averages of the realized (life-span) yields and loss rates for all large ${ }^{14}$ straight corporate bonds outstanding during the period 1900-1944. This was done by the simple device of substituting the contractual yield for the realized yield for those undefaulting bonds for which the realized was in excess of the prospective yield. For such bonds the somewhat dubious gains of the realized over the expected yields-reflecting mainly the effect of the

12. Hickman, Bond Quality, p. 83.

13. Computed from Hickman, Statistical Measures, Table 165, p. 297.

14. More than $\$ 5,000,000$ in size of issue. 
falling level of interest rates on redemption values and final market prices-are eliminated.

This treatment involves the working assumption (some qualifications of which are noted in the next paragraph) that the excesses of realized over prospective yields on undefaulted bonds were due to lower interest rates and not to improved credit prospects. (The unprecedentedly low interest rates during the time of abnormally high call volume and at the end of the experience record were accompanied by stock prices well below half their 1929 high.) In other words, the working assumption is that the bonds which were called at premiums over face would have run to maturity and been redeemed at face value. And that those undefaulted bonds still outstanding at the end which were quoted in the market at liquidating prices such that the realized yields were above the prospective owed the gain to the influence on bond prices of the unprecedentedly low interest rates prevailing at the end of 1943. From these assumptions it would follow that, had there been no change in the level of basic interest rate, the realized yields on both groups of bonds mentioned above would have been equal to, instead of in excess of, their prospective yields. ${ }^{15}$ Substituting the individual prospective yields on this population of bonds for their actual realized yields, in averaging the realized yields of these plus of those of the population of bonds whose actual realized yields were not in excess of their prospective yields, gives us our "modified" realized-yield average for the combined population without loss of the record of any of the bonds.

The lower realized yields and higher loss rates resulting, however, do not give a complete separation of the effects of default and credit impairment from the effects of changes in the interest-rate level. Some of the premium redemptions and higher liquidating values may have resulted from other causes than a decline in the general level of interest rates, perhaps because of better cash position or improved financial prospects of the issuer. Much of the small volume of calls during the first two decades of the century was probably for such reasons. However, it was during the last decade and a half of the period studied that the volume of bonds outstanding was the largest, that the proportion of calls and refundings was

15. It might be argued that the uptilting term structure of the interest rate prevailing toward the end of the experience record would alone have caused the bonds to be higher in price because their terms would have become shorter. But the tilt of the term structure could well have resulted from the descent of interest rates to an abnormally low level. See, for example, R. I. Robinson, The Management of Bank Funds (New York: McGraw-Hill Book Co., Inc., 1951), p. 328. 
abnormally high, and that the interest-rate level became unprecedentedly low. ${ }^{16}$ Inasmuch as the favorable money-market conditions were accompanied by a severe business depression and abnormally high volume of defaults, it seems likely that most of the individual excesses of realized over prospective yields, on the other hand, were due to ease of money rather than to improvement in credit standing of the issuers. It must be recognized also that money-market influences have not been removed from the realized yields and loss rates of those bonds which defaulted or of those bonds whose market values at the close of the experience record were such as to produce a deficiency of realized from expected yield. ${ }^{17}$

Except, then, for minor impurities, the modified averages of realized yields tend to approach, but not quite reach, what the bonds would have yielded without the fortunate and abnormal gains from interest-rate-level changes. The modified averages of loss rates indicate roughly how much of the interest receipts of the entire portfolio would have had to be reserved in order to compensate for losses on the portion of the portfolio that defaulted and on the portion suffering from decline in market value at the end of the study because of credit deterioration.

The modified loss rate represents the rate which it would have been wise to have reserved under a policy of treating any gains over the prospective yield as purely fortuitous. Such a policy has its points, not only because of the questionableness of such "gains" as income for a continuing investor, but also because of the erratic pattern of calls and the imprudence of counting upon the repetition of the abnormally high proportion of them.

The resulting modified averages of realized yields and loss rates are presented in the last two columns of Table 2 (see pp. 431 and 432). ${ }^{18}$ The modified and unmodified average realized yields for the population of most interest to our argument-on all large corporate bonds issued and outstanding between January 1, 1900, and December 1, 1943, and carrying at time of issuance one of the four

16. See Hickman, Corporate Bond Financing, pp. 250, 292, 300, and 129.

17. Limitations of data on the punched cards did not permit this step. The modified averages of realized yields would presumably have been even lower and the resulting loss rates even higher, had we found it possible to remove the effect of interest-level change on their final market values.

18. The population on which they are based is the $\$ 55,181$ million of large issues mentioned on p. 35 of Hickman's Bond Quality, less $\$ 2,743$ million of irregular offerings. 


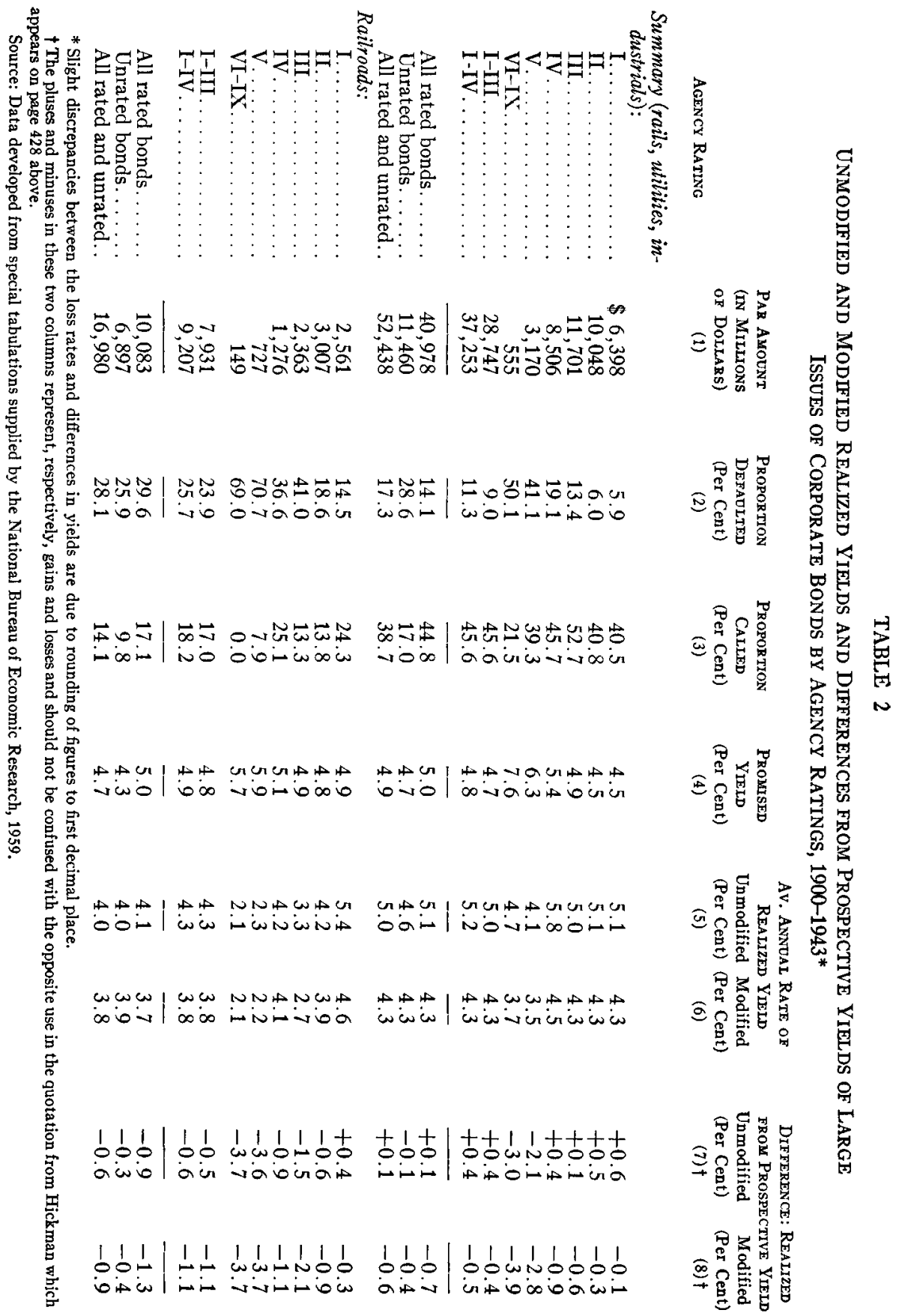




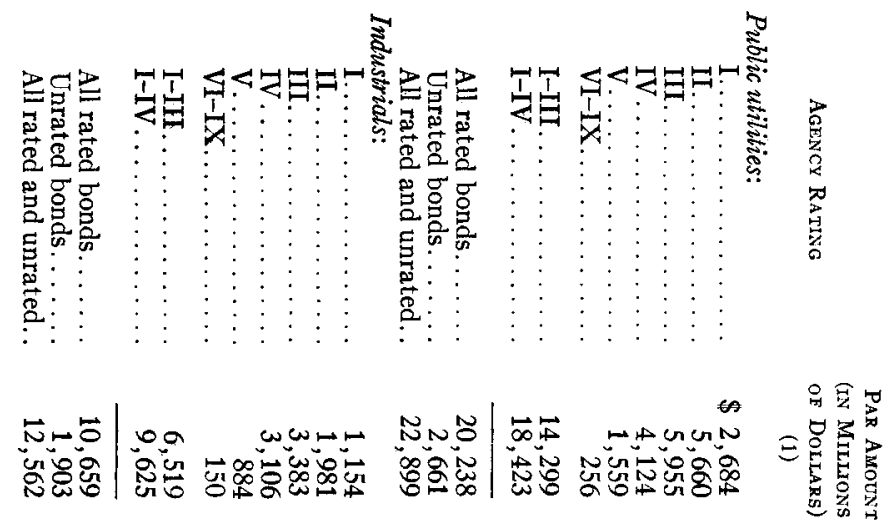

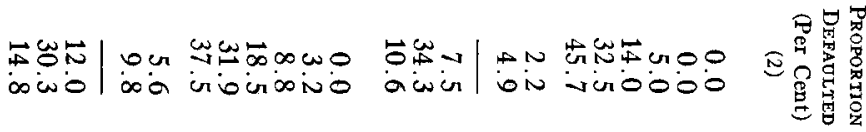

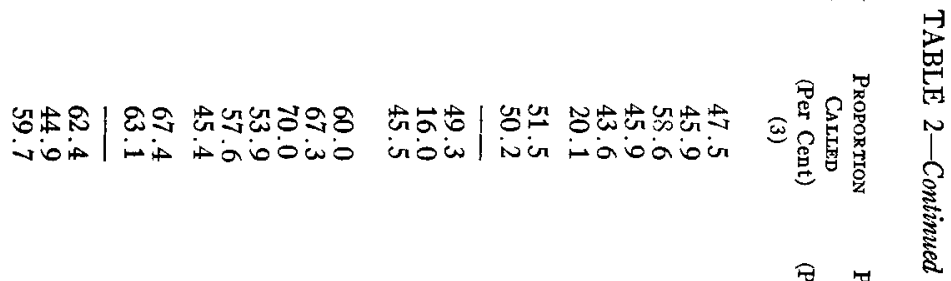

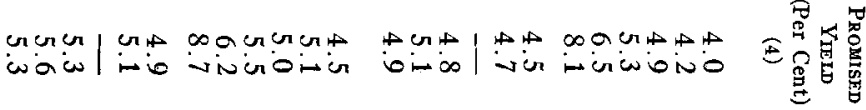

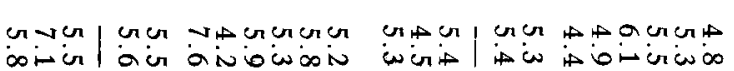

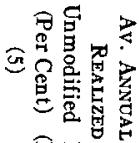

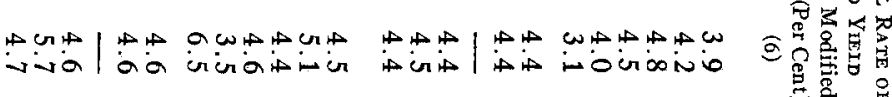

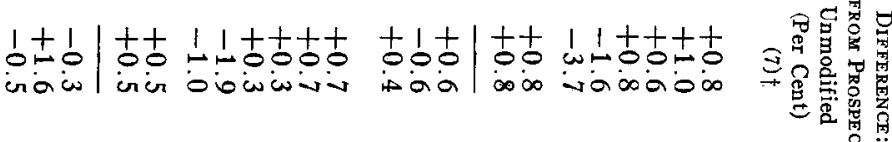

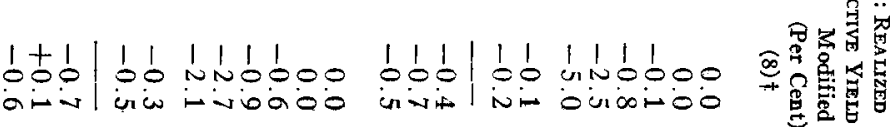


highest agency rating grades-compare with their average promised yields as shown in the accompanying table.

\begin{tabular}{|c|c|c|c|}
\hline \multirow[b]{3}{*}{ AgEncy Rating } & \multicolumn{3}{|c|}{$\begin{array}{l}\text { Weighted Mean Annual Rate } \\
\text { (Per Cent) }\end{array}$} \\
\hline & Promised & Reali & Yield \\
\hline & Yield & Unmodified & Modified \\
\hline $1 \ldots \ldots \ldots \ldots$ & 4.5 & 5.1 & 4.3 \\
\hline II . . . . . . . . & 4.5 & 5.1 & 4.3 \\
\hline III .... & 4.9 & 5.0 & 4.3 \\
\hline IV... & 5.4 & 5.8 & 4.5 \\
\hline I-III. . . . & 4.7 & 5.0 & 4.3 \\
\hline I-IV $\ldots \ldots \ldots \ldots$ & 4.8 & 5.2 & 4.3 \\
\hline
\end{tabular}

* Median of various agency ratings at time of offering: I comparable to AAA, AI+, etc.; II, to AA, AI, etc.; IV, to $\mathrm{BAA}, \mathrm{BI}+$.

It may be of some interest to note that the modified realized yields give a pattern much closer to the uniformity expected by Kirshman than do the unmodified. The pattern of the mean deficiency (loss rate $)^{19}$ of the modified realized from the prospective yields is much more in line with the default frequency and the differentials in risk implied by both the median ratings of the leading rating agencies and the prospective yields (as in the accompanying table). Reservations at the rate of 0.2 per cent of the portfolio per

\begin{tabular}{|c|c|c|}
\hline \multirow[b]{2}{*}{ Agency Rating } & \multicolumn{2}{|c|}{$\begin{array}{c}\text { Gain }(+) \text { or Loss }(-) \text { of } \\
\text { Realized Compared wite } \\
\text { Prospective Yietd } \\
\text { (Per Cent) }\end{array}$} \\
\hline & Unmodified & Modified \\
\hline I. . . & +0.6 & -0.1 \\
\hline & +0.5 & -0.3 \\
\hline & +0.1 & -0.6 \\
\hline & +0.4 & -0.9 \\
\hline III $\ldots \ldots \ldots \ldots$ & +0.4 & -0.4 \\
\hline $\mathbf{I}-\mathbf{I} V \ldots \ldots \ldots \ldots$ & +0.4 & -0.5 \\
\hline
\end{tabular}

annum would have been enough for the real losses from default and credit impairment on a conservative portfolio of the two top agency grades, but almost 1 per cent would have been necessary for a portfolio concentrating in a representative cross-section of fourth-grade corporates. While the modified loss rates indicate that higher reservations out of interest receipts would have been necessary for the riskier issues, the uniformity of modified realized yields compared with the stepping-up of offering yields shows that buyers through their bidding generally anticipated about the correct amount of prospective-yield differential necessary to level the realized yields,

19. Difference between the above arithmetic means of weighted individual prospective and realized yields. Slight discrepancies are due to rounding to first decimal place. 
in the absence of money-market changes. Reference to the other parts of Table 2 shows that the patterns become more erratic, as might be expected, with fragmentation of the universe.

But such departures among the three parts of the universe-railroads, public utilities, and industrials-from the average of all corporates imply that discrimination in selection would have reduced the rate of loss. 